- Systematic reviews of guideline implementation trials have shown that increasing knowledge and skills through audit or education is generally insufficient to achieve significant changes in clinical practice.

- Since guidelines often require clinicians to change their behaviour, basing the design of implementation interventions on psychological models of behaviour change may be an effective means of improving clinical practice and patient outcomes.

- The likelihood of a successful resource-intensive service level trial may also be increased by testing the influence of the intervention on an outcome representative of evidencebased practice, derived from psychological models, in a modelling experiment.

\title{
Can psychological models bridge the gap between clinical guidelines and clinicians' behaviour? A randomised controlled trial of an intervention to influence dentists' intention to implement evidence-based practice
}

\author{
D. Bonetti, ${ }^{1}$ M. Johnston, ${ }^{2}$ N. B. Pitts, ${ }^{3}$ C. Deery, ${ }_{1}^{4}$ I. Ricketts, ${ }^{5}$ M. Bahrami, ${ }_{1}^{6}$ C. Ramsay ${ }^{7}$ and J. Johnston ${ }^{8}$
}

\begin{abstract}
Objective The lag between publication of evidence for clinical practice and implementation by clinicians may be decades. Research using psychological models demonstrates that changing intention is very important in changing behaviour. This study examined an intervention (rehearsing alternative actions) to change dentists' intention to implement evidence-based practice (EBP) for third molar (TM) management.

Design Randomised controlled trial / postal.

Setting Primary care.

Subjects and methods Dentists were randomly selected from the Scottish Dental Practice Board Register, then randomly allocated to intervention or control groups, and sent a questionnaire. The intervention group listed management alternatives to TM extraction prior to their TM extraction intention, and the control group did not. Based on psychological models for reducing a behaviour's frequency (EBP is weighted against TM extraction), prior listing of alternatives should decrease extraction intention.

Main outcome measure Intention to extract TMs.

Results A total of 99 dentists -70 Males, 29 Females; mean age $=41.42$ years $(S D=8.62)$ participated in the study. The intervention significantly influenced intention to extract TMs, as desired. Despite similar background and knowledge of management alternatives, participants in the intervention group had significantly lower intention to extract: control group mean $(S D)=0.39(1.99)$; intervention group mean $(S D)=-0.78$
\end{abstract}

\footnotetext{
${ }^{1}$ Research Fellow, ${ }^{2}$ Professor of Psychology, School of Psychology, University of St Andrews, ${ }^{3}$ Director, ${ }^{6} \mathrm{Clinical}$ Research Fellow, ${ }^{8}$ Researcher, Dental Health Services Research Unit; Dundee Dental Hospital, ${ }^{5}$ Professor of Assistive Systems and Healthcare Computing, ${ }^{7}$ Research Assistant, Department of Applied Computing, University of Dundee, Perth Road, Dundee, ${ }^{4}$ Consultant in Paediatric Dentistry / Honorary Senior Lecturer in Paediatric Dentistry Department of Paediatric Dentistry, Edinburgh Dental Institute,

*Correspondence to: D. Bonetti, School of Psychology, University of St Andrews, St Andrews KY169JU
}

Email:dlb2@st-andrews.ac.uk

\section{Refereed paper}

Received 11.03.02; Accepted 14.01.03

doi:10.1038/sj.bdj.4810565

๑ British Dental Journal 2003; 195: 403-407
(1.89); mean difference $(S E)=1.17(0.42) ; 95 \%$ confidence interval for the difference $=0.34$ to 1.99 .

Conclusion Results suggest this intervention, which successfully influenced a proximal predictor of behaviour pertinent to dental EBP, may result in improved EBP in a service-level trial. Basing implementation interventions and trial methodology on psychological models may effectively bridge the gap between clinical guidelines and practice.

\section{INTRODUCTION}

Variation in clinical practice is an important source of variance in health outcomes. ${ }^{1}$ The purpose of clinical guidelines is to improve patient outcomes by limiting inappropriate variation by outlining evidence-based practice (EBP). ${ }^{2-3}$ This evidence-based approach to care will have an increasing impact on everyday dental practice as more guidelines are introduced. However, it is well-documented (and lamented) that the publication of evidence relating to clinical practice, either as individual studies or as guidelines, does not automatically result in implementation by clinicians. ${ }^{4-5}$ The lag between the provision of evidence and its implementation by clinicians may be decades.

There have been over 240 controlled trials of interventions to influence the behaviour of health professionals. Implementation interventions tend to be aimed at increasing knowledge or skills and include approaches involving the dissemination of guidelines and educational materials, small group education, courses, and audit and feedback. However, systematic reviews of such interventions have shown that increasing knowledge and skills is usually insufficient to achieve changes in clinical behaviour. ${ }^{6-10}$ Yet, expensive implementation interventions continue to be developed and trialled using this unsuccessful paradigm. There is a need both for more effective methods of designing implementation interventions and for more efficient trial methods

Although implementing guidelines often requires clinicians to change their behaviour, there is little evidence that psychological models of behaviour change have been applied to the design of implementation interventions; yet, these models have been suc- 


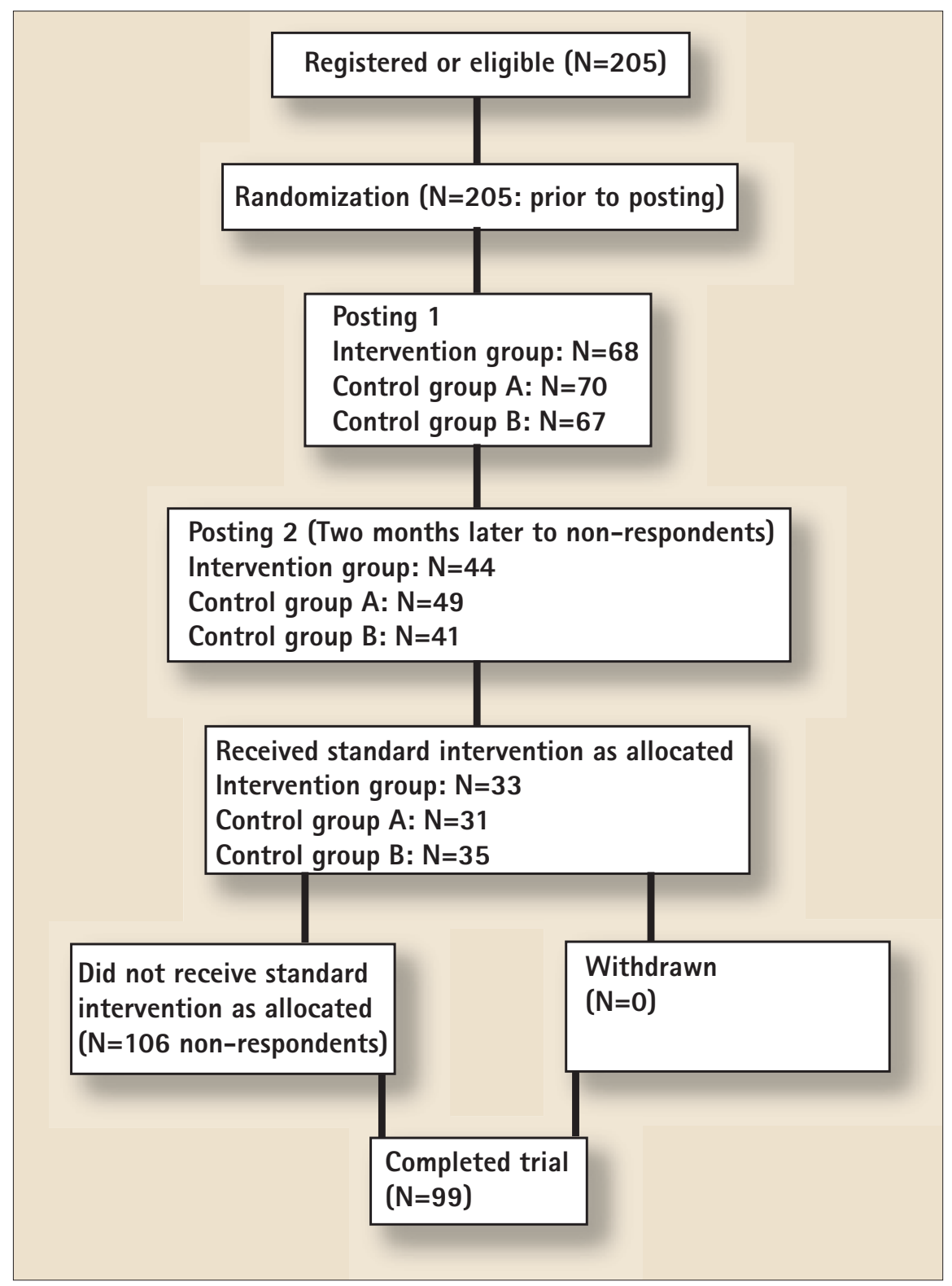

cessfully used to predict variation in many different behaviours in many different populations. ${ }^{11-12}$ They provide a framework showing relationships between psychological variables such as beliefs, attitudes and intentions, and behaviour. These models have also been used to design interventions which have been successful in changing behaviour in many different populations. ${ }^{13}$ One aim of this study was to explore the feasibility of applying psychological models to the design of interventions relating to the implementation of EBP, which has yet to be determined.

In addition to enlightening the design of implementation interventions, psychological models may also inform implementation trial methodology. Currently the main means of testing the success of implementation interventions in different populations is in resource intensive service-level trials. Psychological theories model relationships between cognitive variables and behaviour. They therefore identify variables that are proximal predictors of behaviour. Thus, the likelihood of a successful trial may be considerably increased by first examining the effect of interventions on a proximal predictor of behaviour in a modelling experiment. It is reasonable to expect that an intervention which influences a proxy outcome will be more likely to influence behaviour in a full trial than an intervention which does not.

An example of a proximal predictor of behaviour is intention. While not everyone who intends to perform a behaviour will do so, research using psychological models (particularly the Theory of Planned Behaviour) provides ample evidence that intention to perform a behaviour is nevertheless one of the best predictors of actually performing it. ${ }^{14-15}$ It would be expected that an implementation intervention which successfully influences behavioural intention in a modelling experiment would be more likely to change evidence-based practice in a full trial than one which did not.

The Scottish Intercollegiate Guidelines Network (SIGN) has recently published evidence-based guidelines relating to the care and management of third molars. ${ }^{16}$ The guideline evidence supports the overall reduction of third molar extractions. An implementation intervention relating to the management of third molars would therefore be required to reduce this behaviour. Based on the psychology literature, the likelihood of a successful implementation trial would be increased if it employs an intervention that reduces dentists' intention to perform third molar extractions.

Research using psychological models provides guidance on designing an intention-behaviour intervention. Gollwitzer, Orbell, Sheeran and their colleagues have demonstrated that the likelihood of performing a behaviour can be increased by planning when you intend to perform it. ${ }^{17-19}$ Behavioural approaches point to the need to develop alternative behaviours as the most effective method of eliminating a behaviour. ${ }^{20}$ We therefore sought to 
reduce dentists' intention to extract third molars by having them plan alternative behaviours to extracting third molars.

\section{METHOD}

This was a randomized controlled trial. A preliminary power analysis suggested that a minimum sample of 102 dentists be recruited (across 3 groups: 1 intervention, 2 control subgroups) were required to detect an effect size of 0.40 , alpha $=0.05$, power $=0.95$ (Faul \&t Erdfelder's (1992) Gpower program). Approximately 6 months following the postal distribution of guidelines on the management of third molars to all Scottish dentists, 205 dentists were randomly selected from the Scottish Dental Practice Board List and allocated to a control or intervention group using a random number generator from SPSS. Figure 1 illustrates the trial profile.

Each group was mailed a questionnaire that asked participants to describe their background (post-graduate qualifications; number of years they have been in clinical practice) and their third molar-related experience (number of third molar patients seen in the previous year and month; number of third molar extractions personally performed in these periods). All questionnaires included a general knowledge quiz, derived from research findings relating to third molars. The quiz items covered a wide range of areas, answered on a 3-point scale (correct (score $=1$ ), incorrect (score $=0)$, not sure (score $=0$ ). Example items are: 'an asymptomatic third molar should not be removed when it is buried and in close relationship with the inferior dental nerve'; 'dentigerous cyst formation is rare in association with third molars'. Although background variables (demographic, third molar experience and general knowledge) were not expected to be influenced by the intervention, the information was collected to establish any baseline group differences, since these variables may possibly influence third molar management or the effectiveness of the intervention.

The main outcome measure was intention to extract third molars. This was measured with three questionnaire items. Two items were concerned with the dentists' intention to personally extract third molars: 'of all the patients you see in the next month who require a third molar extraction, approximately how many do you intend to perform?' answered on a 4-point scale (none / some / most / all); 'how likely is it that you will extract a third molar within the next month?' answered on a 7-point scale (unlikely/likely); and one item concerned with following the SIGN guidelines (which support doing less third molar extractions): 'do you intend to follow the third molar guidelines?' answered on a 7-point scale (do / do not). Since the items were answered on different scales, answers were converted to $\mathrm{z}$ scores to ensure equal weighting, and then summed to create a single intention total with higher scores reflecting greater intention to extract third molars.

\section{INTERVENTION}

The intervention involved asking participants to develop an alternative behaviour plan using an open question: 'if a patient reports to you with third-molar related pain and swelling, what alternative treatments to extraction would you consider?' Participants allocated to the intervention group were sent a questionnaire that asked this item prior to the intention items. According to the psychology models, this would have the effect of bringing to mind possible methods of treating third molar problems other than extraction before the formulation of an intention to extract. Having alternative behaviours in mind should thereby inhibit this formulation.

In order to ascertain that groups were equivalent in their specific knowledge (ie management alternatives to third molar extraction), a random sample of participants in the control group were sent a questionnaire which put this item after the intention items and the rest of the control group were sent a questionnaire which did not have this item at all (subgroups A and B, respectively). The questionnaires for participants in all groups were identical except for the placement of this single item.

\section{RESULTS}

Data were analysed using SPSSPC. ${ }^{21}$ Group differences were investigated using Chi-square, $t$-tests and ANOVA (GLM). Relationships between variables were examined using regression analyses.

\section{Participants}

Ninety-nine dentists agreed to participate in the study by returning the questionnaires: 70 males and 29 females, with mean age $=$ 41.42 years ( $\mathrm{SD}=8.62$ years). Nineteen had been qualified less than 10 years, 20/99 had been qualified between 11 and 15 years, 36/99 had been qualified between 16 and 24 years, and 23/99 had been qualified over 25 years. Nineteen had a post-graduate qualification. Participants had seen, on average, 19 third molar patients in the previous year (ranging from 0 to 120) and two patients in the previous month (ranging from 0 to 15), and personally performed 12 third molar extractions in the previous year (ranging from 0 to 75) and 1 in the previous month (ranging from 0 to 13). The mean score on the general third molar knowledge quiz was 65\% (11 out of 17 items; ranging from 0/17 to 15/17) (Cronbach alpha $=0.43)$. For the intervention item, the mean number of treatment alternatives to third molar extraction was 3. The treatment options listed were: antibiotics (51 / 99), mouthwash (30 / 99), oral hygiene instruction (22 / 99), periodontal therapy (21 / 99), operculectomy (17 / 99), monitoring (13 / 99), removal of an opposing third molar (13 / 99), pain relief (11 / 99), grinding (10 / 99), restoration (3 / 99), and removal of a second molar (3 / 99).

In order to ascertain, as far as possible, the comparability of respondents and non-respondents, information about nonrespondents was sought from the Scottish Dental Register. There

Table 1 Mean differences between the control and intervention groups for separate intention items with 95\% confidence intervals ( $\mathrm{Cl}$ )

\begin{tabular}{|c|c|c|c|c|c|}
\hline Intention item & $\begin{array}{l}\text { Control group } \\
\text { Mean (SD) }\end{array}$ & $\begin{array}{l}\text { Intervention group } \\
\text { Mean (SD) }\end{array}$ & Mean difference & Standard error & $95 \% \mathrm{Cl}$ \\
\hline $\begin{array}{l}\text { 1. Of all the patients you see in the } \\
\text { next month who require a third molar } \\
\text { extraction, approximately how many } \\
\text { do you intend to perform? }\end{array}$ & $0.82(1.02)$ & $-0.16(0.94)$ & 0.25 & 0.21 & -0.17 to 0.67 \\
\hline $\begin{array}{l}\text { 2. How likely is it that you will extract } \\
\text { a third molar within the next month? }\end{array}$ & $0.10(0.96)$ & $-0.20(1.06)$ & 0.32 & 0.21 & -0.10 to 0.74 \\
\hline $\begin{array}{l}\text { 3. Do you intend to follow the third } \\
\text { molar guidelines? [The guidelines } \\
\text { support decreasing the number of } \\
\text { third molar extractions.] }\end{array}$ & $0.20(1.07)$ & $-0.40(0.68)$ & 0.60 & 0.18 & 0.25 to 0.95 \\
\hline
\end{tabular}


were no significant differences between the respondents and nonrespondents in either gender $\left(\chi^{2}(1,206)=0.06, p=0.88\right)$ or years qualified $(t(1,196)=1.44, \mathrm{p}=0.15)$.

We were also able to compare the background data of our participants with an independent random sample of Scottish dentists who participated in a study investigating the influence of audit and feedback and computer-assisted learning on third molar management. $^{22}$ There were no significant differences (at $\mathrm{p}<0.05$ ) between participants in this study and participants in the independent study in background variables (age: $t(1,140)=-0.63$, $\mathrm{p}=0.53$; gender: $\chi^{2}(1,150)=1.64, \mathrm{p}=0.24$; years qualified: $t(1$, $147)=-1.11, p=0.27$, or third molar-related experience (patients seen in the previous year: $t(1,127)=-1.29, p=0.20$; or third molar extractions performed in the previous year: $t(1,129)=-1.07$, $\mathrm{p}=0.29$ ).

\section{Equivalence of groups}

There were no significant differences (at $p<0.05$ ) between the control subgroups in any variable (return rate, background, independent or dependent) and so the subgroups were combined into a single control group for all reported analyses (control group $\mathrm{N}=66$, intervention group $\mathrm{N}=33$ ).

There was no significant difference in number of returned questionnaires by group (proportion returned: intervention group $=0.485$, control group $=0.481 ; z=0.054$ ie $<1.96$ ). There were no significant differences between the intervention and control groups in any background variable (age: $t(1,89)=1.63$, $\mathrm{p}=0.11$; gender: $\chi^{2}(1,98)=2.38, \mathrm{p}=0.30$; years qualified: $t(1$, $96)=1.13, p=0.26)$, third molar-related experience (patients seen last year: $t(1,88)=-0.06, p=0.95$; extractions performed last year: $\mathrm{t}(1,87)=-0.29, \mathrm{p}=0.77$; patients seen last month: $t$ $(1,87)=0.43, \mathrm{p}=0.67$; extractions performed last month: $t(1$, $85)=-0.47, p=0.64)$, general third molar-related knowledge ( $t$ $(1,97)=-1.06, p=0.29)$, or in the number of alternative treatment options listed $(t(1,61)=-1.49, \mathrm{p}=0.15)$.

\section{Effect of the intervention on intention}

The intervention was successful in influencing intention to extract third molars. Dentists in the intervention group had significantly lower intention to extract than dentists in the control group: control group mean $=0.39(\mathrm{SD}=1.99)$; intervention group mean $=-$ $0.78(\mathrm{SD}=1.89)$; mean difference $=1.17(\mathrm{SE}=0.42) ; 95 \%$ confidence interval for the difference $=0.34$ to 1.99 .

\section{Post hoc analyses}

The measure of intention had quite low internal reliability (Cronbach alpha $=0.40$ ). Post hoc analyses were performed, exploring the effect of the intervention on each of the three intention items. The pattern was the same for each item as for the overall measure, in that the intervention group scored lower than the control group on each intention item, although, the difference between the groups was significant (at $\mathrm{p}<0.05$ ) for only one of the three items (see Table 1).

Although there were no significant differences between the control and intervention groups in regard to background factors, these factors may still influence the effects of the intervention on dentists' intention to extract third molars. A multiple linear regression analysis was performed to investigate this possibility. However, only group (intervention and control) significantly contributed to the regression equation (at $\mathrm{p}<.05$ level) predicting intention to extract (See Table 2).

\section{DISCUSSION}

Research using psychological models provides evidence that suggests that intention to perform a behaviour is the most reliable predictor of implementing that behaviour. Guideline implementation
Table 2 Results of the multiple linear regression analysis examining the effect of potential confounding factors as well as intervention group on intention to extract third molars (TMs)

\begin{tabular}{|c|c|c|c|c|c|c|c|}
\hline \multirow{3}{*}{$\begin{array}{l}\text { Independent Variable } \\
\text { Upper }\end{array}$} & \multirow[b]{2}{*}{$B^{1}$} & \multirow[b]{2}{*}{$\mathrm{SE}^{2}$} & \multirow[b]{2}{*}{ Beta $^{3}$} & \multirow[b]{2}{*}{$\mathrm{t}$} & \multirow[b]{2}{*}{$\mathrm{p}$} & \multicolumn{2}{|c|}{$\begin{array}{l}\text { 95\% Confidence } \\
\text { Interval for B }\end{array}$} \\
\hline & & & & & & Lower & \\
\hline & -1.05 & 0.44 & -0.25 & -2.38 & 0.020 & -1.93 & -0.17 \\
\hline Gender & -0.02 & 0.51 & -0.01 & -0.05 & 0.959 & -1.05 & 0.99 \\
\hline Age & 0.11 & 0.07 & 0.44 & 1.55 & 0.127 & -0.03 & 0.24 \\
\hline Years qualified & -0.53 & 0.50 & -0.31 & -1.06 & 0.293 & -1.52 & 0.47 \\
\hline Post-grad. qualification & 0.20 & 0.56 & 0.04 & 0.36 & 0.718 & -0.92 & 1.32 \\
\hline Courses attended last year & -0.02 & 0.02 & -0.12 & -1.04 & 0.300 & -0.06 & 0.02 \\
\hline TM patients seen last year & -0.02 & 0.03 & 0.19 & 0.85 & 0.400 & -0.03 & 0.07 \\
\hline TM patients seen last month & -0.47 & 0.25 & -0.49 & -1.90 & 0.062 & -0.96 & 0.02 \\
\hline TM extractions last year & -0.08 & 0.05 & 0.50 & 1.72 & 0.090 & -0.01 & 0.17 \\
\hline TM extractions last month & 0.40 & 0.34 & 0.34 & 1.17 & 0.246 & -0.28 & 1.08 \\
\hline
\end{tabular}

interventions that do not influence intention to implement EBP are therefore unlikely to influence clinical practice. In this trial we used psychological models to develop an intervention, which successfully influenced the intention of dentists to implement third molar EBP in the desired direction. As predicted by behavioural models, planning for alternative behaviours had the effect of reducing intention to perform a specific behaviour incompatible with EBP.

It should be particularly noted that our intention intervention did not add information, unlike other guideline implementation interventions. All participants had received the guidelines before taking part in the study. Participants in the intervention and the control groups were able to demonstrate an equal amount of general knowledge relating to EBP. They were also equally familiar with knowledge relating to possible clinical alternatives to extraction. It was therefore neither the existence of guidelines nor level of knowledge that influenced clinician's intention to implement EBP. This finding may help to explain the general lag in the implementation of EBP and the lack of success of interventions based on educational approaches. Information and knowledge per se are just not enough to motivate EBP.

A limitation of the present study was the return rate, which was just under 50\%. There was no offer of recompense for participating in this study, which suggests that dentists who did respond were quite motivated. It is possible that a degree of motivation may be required for the success of this particular intervention. There also may be some concern over how representative the participants in the study were of dentists in Scotland. Nevertheless, there was no significant difference in the return rate between the intervention and control groups. There were also no significant differences in gender or years registered between respondents and non-respondents, or between the background of participants and an independent sample of Scottish dentists. There is therefore no reason to believe that the response rate or the background of our particular sample of dentists biased the results.

\section{CONCLUSION}

This study examined the effects of an implementation intervention in the form of modelling experiment. The results of this study demonstrate the effectiveness of a theoretically based intervention. The study also complements and extends current findings on implementation interventions in dental practice. It suggests interventions be tested on a proxy outcome for behaviour, derived from theoretical models, as a possible means of increasing the likelihood of success of service-level trials. While caution is warranted in making generalizations about the effect on EBP, the evidence suggests this intervention, which successfully influenced a proximal 
predictor of behaviour pertinent to dental EBP, would be worth investigating in a service-level trial to increase dental EBP.

Applying psychological models to the implementation of dental EBP does not mean ignoring the necessity of educating clinicians in prerequisite knowledge or skills. However, there is ample evidence showing that information transfer is simply not enough to implement changes in clinicians' behaviour. We therefore need to take advantage of research using psychological models specifically directed at behaviour change. These models offer a means of identifying possible target variables, both dependent and independent, for guideline implementation interventions. Designing interventions based on these models also means that the methodology relating to the intervention design can be replicated.

However, using psychological models requires a paradigm shift in guideline implementation studies. The implementation of EBP needs to be conceptualized as behaviour, rather than as ignorance or negligence. Basing implementation interventions on psychological models may be an effective way to bridge the gap between clinical guidelines and clinicians' behaviour.

The authors would like to thank everyone involved in the study, particularly the participating dentists, Marilyn Laird, and Louise Cardno. This project was financed by the NHS RED program.

1 Marteau T M, Johnston M. Health professionals: a source of variance in health outcomes. Psychol Health 1990; 5: 47-58.

2 Woolf S H, Grol R, Hutchinson A, Eccles M, Grimshaw J. The potential benefits, limitations, and harms of clinical quidelines. Br Med J 1999; 318: 527-530.

3 Eccles M, Grimshaw J. (Eds) Clinical Guidelines: from conception to use. Oxford: Radcliffe Press, 2000

4 Petrie J C, Grimshaw J M, Bryson A. The Scottish Intercollegiate Guidelines Network Initiative (SIGN): getting validated guidelines into local practice. Health Bull 1995; 53: $345-348$

5 Oxman A D, Thomson M A, Davis D A, et al. No magic bullets: A systematic review of 102 trials of interventions to improve professional practice. Can Med Assoc J 1995;
153: $1423-1431$

6 Cranney M, Warren E, Barton S, Gardner K, Wallsy T. Why do GPs not implement evidence-based guidelines? A descriptive study. Fam Pract 2001; 18: 359-363.

7 Grimshaw J M, Shirran L, Thomas R, Mowatt G, Fraser C, Bero L, et al. Changing provider behaviour - an overview of systematic reviews of interventions. Med Care 2001; 39: 112-1145

8 McGlone P, Watt R, Sheiham A. Evidence-based dentistry: An overview of the challenges in changing clinical practice. Br DentJ 2001; 190: 636-639.

9 Wensing $M$, Van der Weijden T, Grol R. Implementing guidelines and innovations in general practice: which interventions are effective? Br J Gen Pract 1998; 48: 991 997.

10 Freemantle N, Harvey E L, Wolf F, Grimshaw J M, Grilli R, Bero L A. Printed educational materials: Effects on professional practice and health care outcomes (Cochrane Review). In: The Cochrane Library, 3. Oxford: Update Software, 2001

11 Norman P. Conner M T. The role of social cognition models in predicting attendance at health checks. Psychol Health 1993; 8: 447-462.

12 Hounsa A M, Godin G, Alihonou E, Valois P. An application of Ajzen's theory of planned behaviour to predict mothers' intention to use oral rehydration therapy in a rural area of Benin. Soc Sci Med 1993; 37: 253-261.

13 Conner M, Norman P. (Eds). Predicting health behaviour, Buckingham: Open University Press, 1996.

14 Ajzen I. The theory of planned behaviour. Organizational behaviour and human decision processes 1991; 50: 179-211.

15 Randall D M, Wolff J A. The time-interval in the intention-behaviour relationship: Meta-analysis. BrJSoc Psychol 1994; 33: 405-418.

16 SIGN. Management of unerupted and impacted third molar teeth, Guideline 43. Royal College of Physicians, Edinburgh, 2000.

17 Gollwitzer P M, Brandstatter V. Implementation intentions and effective goal pursuit J Pers Soc Psychol 1997; 73: 186-199.

18 Orbell S, Hodgkins S, Sheeran P. Implementation intentions and the theory of planned behaviour. Pers Soc Psychol Bull 1997; 23: 945-954

19 Sheeran $\mathrm{P}$, Orbell S. Inclined abstainers: a problem for predicting health-related behaviour. Br J Soc Psychol (In press).

20 Gambrill E. Handbook of assessment, intervention, and evaluation. London: JosseyBass, 1977.

21 Norusis M J. SPSS for Windows. Base System User's Guide, Release 5.0. Chicago: SPSS Inc. Marketing Department, 1992

22 Pitts N B, Deery C, Rennie J, McIntosh E, Donaldson C, Ricketts I, Rowe G, Johnston M, Nugent Z. Effective practice? A randomised controlled trial of dissemination and implementation strategies for quidelines for the appropriate extraction of third molar teeth. NHS R\&tD Report, Ref. R2-64 (2001). 